\title{
ANALYSIS OF ADVERSE DRUG REACTIONS SPONTANEOUSLY REPORTED TO ADVERSE DRUG MONITORING CENTRE OF A TERTIARY CARE HOSPITAL-PROSPECTIVE STUDY
}

\author{
GAJANAN P. KULKARNI, LOKESH V. PATIL ${ }^{*}$ \\ Department of Pharmacology, Bidar Institute of Medical Sciences (BRIMS), Bidar, Karnataka \\ Email: drlokeshpatil@gmail.com
}

Received: 20 Oct 2017, Revised and Accepted: 12 Dec 2017

\section{ABSTRACT}

Objective: To assess ADRs with reference to causative drugs, organ systems involved and seriousness of reactions.

Methods: A prospective study conducted over a period of 1 y. The spontaneous adverse drug reactions reported between July 2016 and July 2017 at AMC centre BRIMS, Bidar were analyzed using Naranjo's scale. Causality assessment of suspected drugs involved, system affected, and seriousness of reactions was assessed.

Results: GIT system was most commonly involved, followed by generalized features, skin and appendages, CNS i. e, extrapyramidal system and dizziness, hearing and vestibular systems.

Conclusion: Majority of the ADRs reported were mild to moderate severity and $20 \%$ can be categorized as severe reactions, which needed to treat under hospitalization

Keywords: Adverse drug reaction, Pharmacovigilance, Causality assessment, Serious reactions

(C) 2018 The Authors. Published by Innovare Academic Sciences Pvt Ltd. This is an open-access article under the CC BY license (http://creativecommons.org/licenses/by/4.0/J

DOI: http://dx.doi.org/10.22159/ijcpr.2018v10i1.24403

\section{INTRODUCTION}

Adverse drug reactions (ADRs) constitute a major clinical problem in terms of human suffering and increased health care costs [1]. World Health Organization (WHO) defines an ADR as any noxious, unintended, and undesired effect of a drug, which occurs at doses used in humans for prophylaxis, diagnosis, or cure of a disease [2]. ADRs are responsible for 5-11\% of hospital admissions of which $60-70 \%$ are preventable $[3,4]$. Spontaneous reporting has contributed significantly to successful pharmacovigilance [5].

The main objective of our study was to analyze the ADRs reported in our tertiary care hospital and assessment of severity of the reported ADRs to create a clinical database of commonly occurring ADRs resulting from the use of routine drugs in the hospital so as to prevent and reduce morbidity and bring about better patient care.

\section{MATERIALS AND METHODS}

\section{Study design and site}

This was a prospective observational study conducted at ADR monitoring centre of Bidar Institute of Medical Sciences and Hospital, Bidar, Karnataka. The study was approved by the institutional ethics committee.

\section{Study duration}

The study was carried out over a period of 12 mo from July 2016 to July 2017.

\section{Sample size}

A total of 80 cases reported over a period of 12 mo were included in the study.

\section{Inclusion criteria}

1. Patients of all age, both genders, seeking treatment at BRIMS Bidar and developed ADRs.

2. Patients willing to give written informed consent.
3. Suspected adverse drug reactions reported to the ADR monitoring centre

Exclusion criteria

Patients who were not willing to participate in the study

Study procedure

The suspected adverse drug reactions reported to the pharmacovigilance centre were filled into CDSCO spontaneous ADR reporting forms. A causal relationship was assessed and categorized by Naranjo's algorithm and WHO-UMC causality scale [6]. The severity of each reported ADR was assessed using the criterion developed by modified Hartwig and Siegel scale [7]. All values were expressed in percentages and depicted using tables and charts.

\section{RESULTS}

ADRs were more in males $50(62.5 \%)$ as compared to females 30 (37.5\%) table 1.

The major causative agents for ADRs were antitubercular drugs $(50 \%)$ followed by other antimicrobial agents (25\%) and intravenous fluid (15\%), antihypertensives $(2.5 \%)$, antiepileptic drugs (1.25\%) and others 5(6\%) (table 2).

The most common organ system affected was a gastrointestinal system $(45 \%)$ with symptoms of gastritis, nausea and vomiting followed by generalized features like chills, rigours and palpitations (26.5\%). 20\% of reactions affecting skin and appendages. The central nervous system along with hearing and the vestibular system was affected in $3.75 \%$ (3) each system (table 3).

Assessment of the ADRs using Naranjo's scale showed that 81.25\% (65) of cases were classified as probable, $16.25 \%$ (13) were possible and $2.5 \%$ (2) of cases were in the doubtful category (table 4). On the assessment of ADRs by using WHO-UMC causality assessment scale the number of certain cases was $0 \%$ as no rechallenge was done, $74 \%$ were possible/likely, $25 \%$ were possible and $1 \%$ classified as unlikely (table 5). Severity Assessment by Modified Hartwig and Siegel Scale showed that 39(48.75\%) ADRs were mild, 25 (31.25\%) ADRs were mild and 16 (20\%) ADRs were severe. No lethal effects were reported (table 6). 
Table 1: Gender-wise distribution of ADRS

\begin{tabular}{lll}
\hline Gender & Number of cases & Percentage\% \\
\hline Male & 50 & $62.5 \%$ \\
Female & 30 & $37.5 \%$ \\
\hline
\end{tabular}

Table 2: Drug classes causing ADRs

\begin{tabular}{lll}
\hline Drug classes & Number of ADRs & Percentage\% \\
\hline Antitubercular drugs (Cat 1-ATT+Cat 2-ATT+MDR+XDR TB & 40 & $50 \%$ \\
Antimicrobial agents & 20 & $25 \%$ \\
IVF fluids & 12 & $15 \%$ \\
Anti hypertensive & 2 & $2.5 \%$ \\
Anti epileptic & 1 & 1.25 \\
Others & 5 & $6.25 \%$ \\
\hline
\end{tabular}

Table 3: Organ systems involved in ADRs

\begin{tabular}{lll}
\hline Organ systems involved & Number of cases & Percentage \% \\
\hline GIT & 36 & $45 \%$ \\
Generalized features & 21 & $26.25 \%$ \\
Skin and appendages & 16 & $20 \%$ \\
CNS & 3 & $3.75 \%$ \\
Hearing and vestibular system & 3 & $3.75 \%$ \\
\hline
\end{tabular}

Table 4: Causality assessment using naranjo's algorithm

\begin{tabular}{lll}
\hline Type of reaction & Number of cases & Percentage\% \\
\hline Probable & 65 & $81.25 \%$ \\
Possible & 13 & $16.25 \%$ \\
Doubtful & 2 & $2.5 \%$ \\
\hline
\end{tabular}

Table 5: WHO-UMC assessment scale

\begin{tabular}{ll}
\hline Type of reaction & Percentage (\%) \\
\hline Certain & $0 \%$ \\
Probable/likely & $74 \%$ \\
Possible & $25 \%$ \\
Unlikely. & $1 \%$ \\
Conditional/unclassified & $0 \%$ \\
Unassessable/unclassifiable & $0 \%$ \\
\hline
\end{tabular}

Table 6: Severity assessment by modified hartwig and siegel scale

\begin{tabular}{lll}
\hline Type or severity of ADRs & Number of cases & Percentage \% \\
\hline Mild & 39 & 48.75 \\
Moderate & 25 & 31.25 \\
Severe & 16 & 20 \\
\hline
\end{tabular}

\section{DISCUSSION}

In this prospective observational study all spontaneously reported ADR to AMC, BRIMS Bidar was analyzed for gender wise incidence, drug classes responsible for ADRs and organ system involved. The reported ADRs were evaluated, causality assessment was done using Naranjo's algorithm and severity assessed using Hartwig Seigel's severity scale.

In this study, we found that ADRs were more in males 50 (62.5\%) as compared to females $30(37.5 \%)$. This finding is was contradictory to previous studies by Bhabhor et al. and Ramesh $\mathrm{M}$ et al. The reason for this finding might be due to underreporting in the females in rural set up like Bidar. $[8,9]$.

In our study, the major causative agents for ADRs were antitubercular drugs $(50 \%)$ followed by other antimicrobial agents (25\%) and intravenous fluid (15\%), antihypertensives $(2.5 \%)$, antiepileptic drugs (1.25\%) and others (6\%).

These findings are similar to other studies, where antimicrobial agents were most commonly implicated in ADRs $[10,11]$.
Antitubercular antimicrobials were top among the drugs responsible for ADRs. The incidence of spontaneous reporting for ADR due to the antitubercular drug is also high due to DOTs program.

Among other antimicrobials third-generation cephalosporins, other Blactam antibiotics were responsible for serious cutaneous reactions. These findings are in line with the previous studies [12-14].

The cardiovascular (antihypertensives) and CNS drugs (antiepileptics) were also responsible for $5.6 \%$ of total ADRs.

The ADR caused by NSAIDS was less $(<1 \%)$ in our studies as compared to other studies done by Bhabhor et al. this might be due to underreporting and self-medication for the ADRs caused by NSAIDs.

The most common organ system affected was a gastrointestinal system (45\%) with symptoms of gastritis, nausea and vomiting followed by generalized features like chills, rigours and palpitations (26.5\%). $20 \%$ of reactions affecting skin and appendages such as rash, urticaria and itching which is in accordance with other such studies done by Shrivastava M et al. and Chan AL et al. [14, 15]. 
Assessment of the ADRs using Naranjo's scale showed that $81.25 \%$ (65) of cases were classified as probable, $16.25 \%$ (13) were possible and $2.5 \%$ (2) of cases were in doubtful category. On the assessment of ADRs by using WHO-UMC causality assessment scale the number of certain cases was $0 \%$ since rechallenge was not done, $74 \%$ were possible/likely, $25 \%$ were possible and $1 \%$ classified under the unlikely category. Severity Assessment by Modified Hartwig and Siegel Scale showed that 39(48.75\%) ADRs were mild, 25 (31.25\%) ADRs were moderate and $16(20 \%)$ ADRs were severe which is in line with a study done by Bhabhor et al. ${ }^{8}$ No lethal effects were reported. Our study analyzed the ADRs reported in our tertiary care hospital and assessment of severity of the reported ADRs was done and it generated a clinical database of commonly occurring ADRs resulting from the use of routine drugs in the hospital. It would help to prevent and reduce morbidity and bring about better patient care.

\section{CONCLUSION}

The pattern of ADRs reported in our hospital is comparable with the results of studies conducted in other hospitals. Antimicrobial agents were causing maximum ADRs. This study provides a database of ADRs due to common drugs used in our hospital, which will help clinicians for optimum and safe use of these drugs. Hence effective implementation of ADR monitoring would result in better and safe use of these drugs which would ultimately result in better patient care.

\section{AUTHORS CONTRIBUTIONS}

All the author have contributed equally

\section{CONFLICT OF INTERESTS}

Declared none

\section{REFERENCES}

1. Classen DC, Pestotnik SL, Evans RS, Lloyd JF, Burke JP. Adverse drug events in hospitalized patients, excess length of stay, extra costs and attributable mortality. JAMA 1997;227:301-6.

2. World Health Organization. Safety of Medicines. A guide to detecting and reporting adverse drug reactions. Geneva, Switzerland: World Health Organization. HO/EDM/QSM/2002; 2002.

3. Beijer HJ, de Blaey CJ. Hospitalisations caused by adverse drug reactions (ADR): a meta-analysis of observational studies. Pharm World Sci 2002;24:46-54.
4. Bates DW, Cullen DJ, Laird N, Petersen LA, Small SD, Servi D, et al. Incidence of adverse drug events and potential adverse drug events. Adverse drug event prevention study group. JAMA 1995;274:29-34.

5. Lexchin J. Is there a role for spontaneous reporting of adverse drug reactions? CMA J 2006;174:191-2.

6. Naranjo CA, Busto U, Sellers EM, Sandor P, Ruiz I, Roberts EA, et al. A method for estimating the probability of adverse drug reactions. Clin Pharmacol Ther 1981;30:239-45.

7. Hartwig SC, Siegel J, Schneider PJ. Preventability and severity assessment in reporting adverse drug reactions. Am J Hosp Pharm 1992;49:2229-32.

8. Bhabhor PH, Patel KP, Vohata R, Patel PB, Desai N. Adverse drug reactions in a tertiary care teaching hospital in India: analysis of spontaneously reported cases. Int J Basic Clin Pharmacol 2014;3:1078-85.

9. Ramesh M, Pandit J, Parthasarthi G. Adverse drug reactions in a south Indian hospital-their severity and cost involved. Pharmacoepidemiol Drug Saf 2003;37:687-92.

10. Murphy BM, Frigo LC. Development, implementation, and results of a successful multidisciplinary adverse drug reaction reporting program in a university teaching hospital. Hosp Pharm 1993;28:1199-204.

11. Hettihewa LM, Sirisena B. Casualty assessment and the severity of the adverse drug reactions (adr) actively detected in hospital in patients in tertiary care hospital Sri Lanka: a Prospective observational survey. Asian J Res Biol Pharm Sci 2014;2:1-10.

12. Johnston PE, France DJ, Byrne DW, Murffy HJ, Lee B, Stiles RA, et al. Assessment of adverse drug events among patients in a tertiary care medical centre. Am J Health Syst Pharm 2006;63:2218-27.

13. Shrivastava M, Uchit G, Chakravarti A, Joshi G, Mahatme M, Chaudhari H. Adverse drug reactions reported in Indira Gandhi Government Medical College and Hospital, Nagpur. J Assoc Physicians India 2011;59:1-4.

14. Rajakannan T, Mallaya S, Lakshminarasu M, Rajendra SD. Intensive monitoring of Adverse drug reactions in a south Indian tertiary care hospital. J Clin Pharmacol 2012;52:559-65.

15. Chan AL, Lee HY, Ho CH, Cham TM, Lin SJ. Cost evaluation of adverse drug reactions in hospitalized patients in Taiwan: a prospective, descriptive, observational study. Curr Ther Res Clin Exp 2008;69:118-29. 